\title{
ESTUDO DO DESEMPENHO DE RESÍDUO DE ACIARIA ELÉTRICA INCORPORADO EM MATRIZ POLIMÉRICA*
}

\author{
Maurício Gammertt Röhnelt ${ }^{1}$ \\ Cristiane Krause Santin ${ }^{2}$ \\ Tatiana Louise Avila de Campos Rocha ${ }^{3}$ \\ Leandro Gianluppi ${ }^{4}$
}

\section{Resumo}

A pesquisa em questão trata-se do aproveitamento e aplicação da escória de aciaria elétrica, um subproduto residual do processo de refino do aço. A força propulsora para realização deste projeto está associada à utilização do resíduo: a quantidade gerada é maior que a quantidade aproveitada, uma vez que este subproduto tem como limitante de uso o fenômeno de expansão volumétrica que compromete obras de engenharia. No presente estudo, a escória foi micronizada, caracterizada e incorporada em uma matriz polimérica para obtenção de um novo produto com propriedades vedantes. Os artefatos produzidos foram submetidos a vários ensaios mecânicos, químicos e de caracterização conforme requisitado pela norma NBR 15750. Após a análise dos resultados, concluiuse que os compostos constituídos pelo resíduo apresentaram melhores propriedades vedantes que o grupo controle de referência. Além disso, verificaram-se melhores condições de processamento nos compostos com escória de aciaria micronizada. Obteve-se, portanto, um produto ecológico, mais viável economicamente, com propriedades que atendem a uma especificação. Dessa forma, difundiu-se a aplicação do resíduo para outros ramos industriais, agregando a este maior valor comercial, promovendo assim a sustentabilidade por meio da substituição de matérias-primas provenientes de recursos não renováveis pela escória de aciaria elétrica.

Palavras-chave: Escória de aciaria elétrica; Indústria de elastômeros; Sustentabilidade.

\section{PERFORMANCE STUDY OF ELECTRIC ARC FURNACE (EAF) RESIDUE INCORPORATED INTO POLYMERIC MATRIX}

\begin{abstract}
This research refers to reuse and application of Electric Arc Furnace (EAF) slag, a residual subproduct from the refining process of steel. The driving force for carrying out this development comes from the critical situation associated to EAF slag utilization: the amount generated is greater than the amount recovered, once this subproduct has as limiting use the phenomenon of volumetric expansion, which affect engineering works. In the current study, the slag was micronized, characterized and incorporated into a polymeric matrix to obtain a product with sealing properties. The manufactured artifacts were subjected to several mechanical, chemical and characterization tests required by NBR 15750 standard. After results evaluation, it has concluded that slag compounds have showed the best sealing properties than the reference control group. In addition, it has found better processing conditions in micronized slag compounds. Therefore, it hasn't just created a new ecological product, more economically viable, with properties that comply with a specification, but it has encountered a new application to EAF Slag. This way, it has been diffused the EAF slag application to other industrial branches, adding this more commercial value as well as promoting the sustainability through the replacing of non-renewable raw materials by the micronized slag.

Keywords: Electric arc furnace slag; Rubber industry; Sustainability.

1 Estudante de Engenharia Química, Técnico de Mecânica Industrial, Auxiliar Técnico, itt Fuse-Instituto Tecnológico em Ensaios e Segurança Funcional, Universidade do Vale do Rio dos Sinos (Unisinos), São Leopoldo, Rio Grande do Sul, Brasil.

2 Química, Mestrado Química, Doutorado Ciência dos Materiais, Prof., Unisinos, São Leopoldo, RS, Brasil.

3 Química Industrial, Mestrado Engenharia de Materiais, Doutorado Ciência dos Materiais, Coordenação Engenharia de Materiais, Unisinos, São Leopoldo, RS, Brasil.

4 Eng. de Plásticos, Pós-Graduação em Engenharia de Segurança do Trabalho, Assistente Técnico, itt FuseInstituto Tecnológico em Ensaios e Segurança Funcional, Unisinos, São Leopoldo, RS, Brasil.
\end{abstract}




\section{INTRODUÇÃO}

Com o advento de novas tecnologias avançadas, as quais promoveram um desenfreado desenvolvimento industrial ao longo das últimas décadas, maiores foram as preocupações por parte da Indústria em empregar mecanismos limpos e sustentáveis inerentes ao processo de produção. Isto porque, em diversos ramos industriais, são utilizadas determinadas matérias-primas e insumos para a fabricação de produtos. E desse processo de manufatura, resultam diversos resíduos sólidos, os quais são classificados como: perigosos, não perigosos, inertes e não inertes, de acordo com a ABNT NBR 10004:2004.

Dentre os setores industriais que mais obtiveram crescimento de investimentos no Brasil, entre os anos de 2005 e 2013, a Siderurgia foi o que apresentou o segundo maior índice percentual $(58,7 \%)$, perdendo apenas para o de Petróleo e Gás $(88,2 \%)$ [1].

No setor siderúrgico, por sua vez, são geradas grandes quantidades de resíduos sólidos oriundos do processo de produção do aço. O processo siderúrgico gera aproximadamente $600 \mathrm{~kg}$ de resíduos e co-produtos por tonelada de aço produzida [2]. O agregado siderúrgico, por sua vez, é o principal resíduo gerado $(77 \%)$, seguido das lamas (13\%), e dos pós (10\%) [3]. Os principais tipos de escória gerada são provenientes do processo de alto-forno, aciaria LD e aciaria elétrica.

Devido a grande geração de escória, nos últimos anos foi crescente a tendência do setor produtivo siderúrgico em ofertá-la a outros setores, os quais podem utilizá-la como matéria-prima ou insumo, minimizando assim um de seus problemas no processo de produção: o descarte. Esta parceria já vem ocorrendo entre o setor siderúrgico e o setor da construção civil. As escórias de alto-forno a coque, geradas no processo de produção do ferro-gusa, são consumidas em larga escala para a produção de cimento Portland [4].

Entretanto, a escória de aciaria elétrica gerada pelo setor siderúrgico ainda não se consolidou totalmente no mercado cimenteiro, pois apresenta como limitante de utilização o problema de expansão (instabilidade volumétrica causada principalmente pela Cal), que pode comprometer obras de engenharia se utilizada incorretamente.

O volume mundial de escória gerada em aciaria é da ordem de 84 milhões de toneladas por ano [5]. Estima-se, que em 2016 a geração de escória de aciaria no Brasil será em torno de 10,7 milhões de toneladas, sendo 3,0 milhões correspondentes à escória de aciaria elétrica [2].

A partir do cenário crítico exposto, avaliou-se, portanto, a possibilidade de incorporar tal resíduo siderúrgico em uma matriz polimérica, a fim de obter um produto vedante com propriedades físico-mecânicas e químicas que atendem uma especificação.

A utilização de resíduos pode ajudar a conservar os recursos naturais e reduzir a demanda por matérias-primas convencionais. Ao mesmo tempo, podem ajudar a preservar o meio ambiente, permitindo a redução da quantidade de resíduos, que em geral causam degradação ambiental [6].

Logo, através da micronização do resíduo há possibilidade de aplicá-lo como carga na Indústria de Transformação de Elastômeros, promovendo a redução de custo dos artefatos desenvolvidos, bem como conferindo específicas propriedades físicomecânicas, químicas e de processamento.

Além disso, aplicando a escória de aciaria elétrica em outro ramo industrial diferente do da construção civil, no qual não se consolidou totalmente -, haverá sua valorização comercial, o que de fato pode estimular o desenvolvimento de novas 
alternativas de seu aproveitamento e gerenciamento.

Dessa forma, o presente projeto tem como principal objetivo avaliar o desempenho da escória de aciaria elétrica micronizada como carga na Indústria de Elastômeros, difundindo assim sua aplicação em outros setores industriais, bem como promovendo a sustentabilidade através da ampliação de seu aproveitamento.

\section{MATERIAIS E MÉTODOS}

\subsection{Materiais}

Todos os aditivos utilizados para o desenvolvimento do estudo (incluindo resinas, elastômeros, plastificantes, cargas, agentes de cura) foram adquiridos por meio de doações provenientes de empresas da indústria de borracha local.

A escória de aciaria elétrica foi coletada em uma das sedes da empresa Harsco Metals \& Minerals, localizada no município de Sapucaia do Sul - RS, em uma das usinas de produção de aço de uma empresa siderúrgica brasileira.

O resíduo siderúrgico foi submetido a um tratamento físico de micronização antes de sua incorporação na matriz polimérica.

\subsection{Preparação dos Compostos poliméricos}

\subsubsection{Definição das formulações}

A formulação de referência (grupo controle) empregada na experimentação é constituída de uma matriz elastomérica nitrílica específica aplicada na fabricação de anéis de vedação para tubulações de PVC.

Ao formular um composto elastomérico, procura-se: assegurar que o produto final tenha as propriedades requeridas para determinada aplicação, alcançar as características necessárias para a eficiente utilização dos equipamentos disponíveis, e, por fim, obter as propriedades e processabilidade desejáveis no mais baixo custo possível.

Dessa forma, o resíduo foi adicionado e incorporado a fim de avaliar sua influência nas condições de processamento, e, principalmente, nas propriedades físicomecânicas e químicas requeridas do produto final.

Um dos fatores determinantes considerados para a escolha de o-rings como artefatos de estudo, deve-se pelo fato destes serem aplicados no interior das tubulações, diretamente em contato com a água, a qual é o agente principal no processo de expansão da escória (promovido por meio de uma reação de hidratação entre os óxidos livres presentes, principalmente $\mathrm{CaO}$ e $\mathrm{MgO}$ ).

Portanto, concomitantemente foi avaliada a influência do resíduo nas propriedades finais do produto, bem como sua expansibilidade volumétrica quando incorporado na matriz polimérica.

A partir do grupo controle foram definidas duas outras formulações, nas quais a carga reforçante (negro-de-fumo) presente foi substituída em $20 \%$ e $30 \%$ pela escória de aciaria. As formulações foram identificadas como: Referência (grupo controle), SLAG20 (20\% de resíduo) e SLAG30 (30\% de resíduo).

\subsubsection{Processamento dos compostos}

Os ingredientes de cada formulação foram pesados e posteriormente processados em uma câmara de mistura HAAKE RHEOMIX 3000p, a qual é composta por um 
sistema inteligente comandado por um reômetro de torque modular para a simulação de processos industriais em laboratório ou em plantas-piloto.

Os ingredientes foram processados em um tempo de 15 minutos, com velocidade de mistura (rotores) de $60 \mathrm{rpm}$ e temperatura das zonas da câmara a $80^{\circ} \mathrm{C}$.

Após a mistura, os compostos foram laminados em um misturador aberto e submetidos a um ensaio de obtenção de curva reométrica segundo a norma ASTM D 5289-12 para determinação dos parâmetros de vulcanização.

Por fim, os compostos foram vulcanizados em uma prensa pneumática a $180^{\circ} \mathrm{C}$.

\subsection{Testes de Caracterização}

Para a caracterização da escória de aciaria, bem como dos compostos elastoméricos confeccionados, foram realizadas as seguintes análises: Termogravimetria (TGA); Calorimetria Exploratória Diferencial (DSC); Microscopia Eletrônica de Varredura (MEV).

\subsection{Testes Físico-mecânicos e Químicos}

Para qualificação dos compostos utilizados como anéis de vedação, são realizados os seguintes ensaios solicitados, conforme anexo $\mathrm{H}$ - Requisitos para os Anéis de Elastômeros Empregados em Tubos de PVC-O para Uso em Esgoto, presente na norma NBR 15750: Determinação da Resistência à Tração segundo ISO 37; Determinação da Dureza Shore A segundo ISO 7619-1; Imersão em Líquido para Elastômeros segundo ISO 1817; Envelhecimento Acelerado em Estufa segundo ISO 188 - Método B; Deformação Permanente à Compressão segundo ISO 815;

\section{RESULTADOS E DISCUSSÃO}

\subsection{Análise da Processabilidade em HAAKE RHEOMIX 3000p}

Misturadores como o HAAKE, que são constituídos por sistemas de integração de potência para a análise da energia consumida, possuem dispositivos que medem e registram continuamente tal potência em cada fase do processo de mistura [7].

A potência ou torque para um dado instante é função da viscosidade adquirida pelo composto: quando está com alta viscosidade, é necessária uma potência alta para girar os rotores; conforme vai reduzindo sua viscosidade, a potência consumida decresce.

Analisando os dados obtidos em cada processo de mistura, verificou-se que o resíduo micronizado conferiu a ambos os compostos do grupo experimental (SLAG20 e SLAG30) melhor processabilidade, visto que após a adição das cargas, o pico máximo de torque observado foi de aproximadamente $150 \mathrm{Nm}$, diferente do apresentado pelo composto de referência $(200 \mathrm{Nm})$. Logo, os rotores tiveram de realizar menor esforço de cisalhamento para incorporar a mistura. Além disso, nos pontos de adição das cargas, notou-se diferença de temperatura entre as amostras: o composto de referência apresentou $90^{\circ} \mathrm{C}$ enquanto os demais compostos, SLAG20 e SLAG30, apresentaram em torno de $85^{\circ} \mathrm{C}$, denotando que houve menor aquecimento e gasto energético. 


\subsection{Testes de Caracterização}

\subsubsection{Termogravimetria (TGA)}

Por meio da análise termogravimétrica pode-se concluir que a escória de aciaria elétrica não provocou nenhuma alteração no processo de degradação dos compostos quando submetidos a uma programação controlada de temperatura.

Além disso, não houve significativas variações de perda de massa ao comparar as amostras, exceto no percentual de resíduos remanescentes do processo. Isto se deve pelo fato de a escória de aciaria elétrica aplicada se enquadrar no grupo de cargas inorgânicas, as quais se degradam a uma temperatura acima da máxima utilizada no ensaio $\left(789,43^{\circ} \mathrm{C}\right)$. O percentual de resíduos gerados para as amostras Referência, SLAG20 e SLAG30, foram, respectivamente, 3,652\%; 11,48\%; 14,95\%.

\subsubsection{Calorimetria Exploratória Diferencial (DSC)}

Com a realização desta análise pode-se concluir que o resíduo siderúrgico não exerceu influências na Temperatura de Transição Vítrea ( $\mathrm{Tg}$ ) do elastômero.

As Tg's encontradas para as amostras de Referência, SLAG20 e SLAG30 foram, respectivamente: $-32,21^{\circ} \mathrm{C} ;-31,72^{\circ} \mathrm{C}$ e $-31,41^{\circ} \mathrm{C}$.

\subsubsection{Microscopia Eletrônica de Varredura (MEV)}

Segue abaixo na Figura 1 uma imagem representativa obtida no microscópio eletrônico de varredura. Nota-se que, morfologicamente, as partículas do resíduo não apresentam estrutura bem definida e há uma variação na sua granulometria.

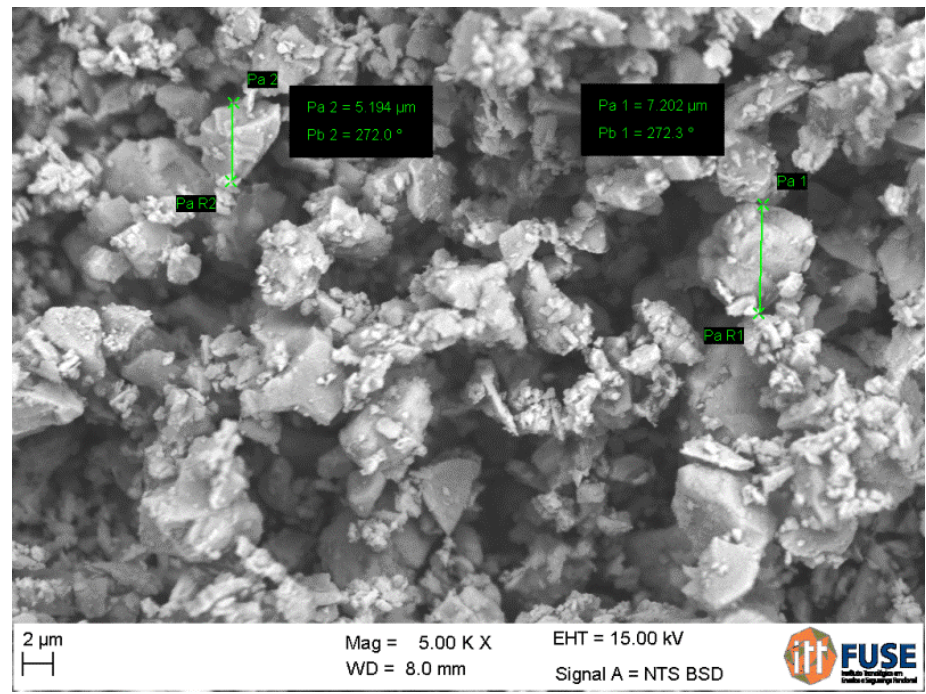

Figura 1. Análise de Microscopia Eletrônica de Varredura

\subsection{Testes Físico-mecânicos e Químicos}

Na Tabela 1 encontram-se os resultados obtidos para os ensaios físico-mecânicos e químicos requisitados pela NBR 15750. 
Tabela 1. Resultados dos ensaios físico-mecânicos e químicos realizados

\begin{tabular}{|c|c|c|c|c|c|c|}
\hline Ensaio Realizado & Norma & $\begin{array}{l}\text { NBR } \\
15750\end{array}$ & Referência & SLAG20 & SLAG30 & Status \\
\hline $\begin{array}{c}\text { Tensão de Ruptura } \\
(\mathrm{MPa})\end{array}$ & ISO 37 & $\begin{array}{l}\text { Mín. } 9 \\
\text { MPa }\end{array}$ & $\begin{array}{l}15,1 \mathrm{MPa} \pm \\
0,53\end{array}$ & $\begin{array}{l}15,1 \mathrm{MPa} \\
\pm 0,55\end{array}$ & $\begin{array}{l}15,0 \mathrm{MPa} \\
\pm 0,02\end{array}$ & Aprovado \\
\hline Alongamento (\%) & ISO 37 & $\begin{array}{l}\text { Mín. } \\
370 \%\end{array}$ & $\begin{array}{l}460 \% \\
\pm 18,25\end{array}$ & $\begin{array}{l}620 \% \\
\pm 36,76\end{array}$ & $\begin{array}{l}630 \% \\
\pm 13,35\end{array}$ & Aprovado \\
\hline Dureza Shore A (Pts) & $\begin{array}{l}\text { ISO } \\
7619-1\end{array}$ & $46-56$ & $56 \pm 0,90$ & $51 \pm 1$ & $50 \pm 0,40$ & Aprovado \\
\hline $\begin{array}{c}\text { Imersão em Água } \\
\text { Destilada }\left(168 \mathrm{~h} / 70^{\circ} \mathrm{C}\right) \\
-\Delta \text { Volume }(\%)\end{array}$ & $\begin{array}{l}\text { ISO } \\
181\end{array}$ & $\begin{array}{c}-1 \% \text { a } \\
+8 \%\end{array}$ & $\begin{array}{l}+5,9 \% \\
\pm 0,14\end{array}$ & $\begin{array}{l}+6,7 \% \\
\pm 0,43\end{array}$ & $\begin{array}{l}+5,9 \% \\
\pm 0,28\end{array}$ & Aprovado \\
\hline $\begin{array}{c}\text { Imersão em Óleo IRM } \\
903\left(72 \mathrm{~h} / 70^{\circ} \mathrm{C}\right) \\
\Delta \text { Volume }(\%) \\
\end{array}$ & $\begin{array}{l}\text { ISO } \\
181\end{array}$ & $\begin{array}{c}-5 \% \text { a } \\
50 \%\end{array}$ & $\begin{array}{l}+4,2 \% \\
\pm 0,29\end{array}$ & $\begin{array}{l}+5,5 \% \\
\pm 0,52\end{array}$ & $\begin{array}{l}+4,4 \% \\
\pm 0,37\end{array}$ & Aprovado \\
\hline $\begin{array}{c}\text { Variação Tensão } \\
\text { Ruptura Após } \\
\text { Envelhecimento (\%) }\end{array}$ & $\begin{array}{l}\text { ISO } \\
188\end{array}$ & $\begin{array}{l}\text { Máx. - } \\
20 \%\end{array}$ & $+1 \%$ & $-5 \%$ & $-8 \%$ & Aprovado \\
\hline $\begin{array}{c}\text { Variação Alongamento } \\
\text { Após Envelhecimento } \\
(\%)\end{array}$ & $\begin{array}{l}\text { ISO } \\
188\end{array}$ & $\begin{array}{l}-30 \% \text { a } \\
+10 \%\end{array}$ & $+9 \%$ & $-8 \%$ & $-6 \%$ & Aprovado \\
\hline $\begin{array}{c}\text { Variação Dureza } \\
\text { Shore A Após } \\
\text { Envelhecimento (Pts) }\end{array}$ & $\begin{array}{l}\text { ISO } \\
188\end{array}$ & $-5 a+8$ & +1 & 0 & +1 & Aprovado \\
\hline $\begin{array}{l}\text { Deformação } \\
\text { Permanente a } \\
\text { Compressão } \\
\left(24 \mathrm{~h} / 70^{\circ} \mathrm{C}\right)\end{array}$ & $\begin{array}{l}\text { ISO } \\
188\end{array}$ & $\begin{array}{l}\text { Máx. } \\
20 \%\end{array}$ & $17 \%$ & $13 \%$ & $13 \%$ & Aprovado \\
\hline
\end{tabular}

A partir da tabela supracitada, pode-se concluir que os compostos elastoméricos desenvolvidos com a escória de aciaria apresentaram todas as propriedades necessárias requisitadas pela NBR 15750, validando seu uso como anéis de vedação para tubulações de PVC.

\section{CONCLUSÃO}

Com o desenvolvimento do projeto tecnológico em questão, pode-se avaliar os benefícios técnicos e ambientais obtidos por meio incorporação da escória de aciaria elétrica em uma matriz polimérica.

A aplicação do resíduo siderúrgico em outros ramo industrial implica principalmente na redução do consumo de recursos naturais não renováveis, visto que houve substituição de matérias-primas provenientes da decomposição de combustíveis fósseis (negros-de-fumo). Logo, a presente iniciativa enfatiza a utilização dos Mecanismos de Desenvolvimento Limpo (MDL) na Indústria, os quais estimulam o desenvolvimento sustentável por meio da redução de emissão dos gases do efeito estufa.

O estudo em questão promoveu a lei $n^{\circ} 12305$, a qual institui a Política Nacional de Resíduos Sólidos (PNRS). A utilização da escória de aciaria elétrica micronizada reduz a necessidade de aterros de resíduos industriais, uma vez que a disposição do que era antes um resíduo é substituída pela reciclagem e aplicação de um produto. 
Tecnicamente, através da análise do processo de mistura dos compostos, concluiuse que as amostras SLAG20 e SLAG30 apresentaram melhores condições de processabilidade comparado à amostra Referência. Além disso, verificou-se que os compostos incorporados com o resíduo apresentarem maior resistência à Deformação Permanente a Compressão (DPC), indicando que estes, caso utilizados como o-rings, promoveriam melhores propriedades de vedação.

Em nível de aplicação, pode-se dizer que o ensaio de DPC é o mais solicitado, visto que está diretamente relacionado à propriedade de vedação dos anéis de elastômero. Isto porque, tal propriedade é função da memória elástica, a qual está ligada à força de reação imposta pela componente elástica de um elastômero quando comprimido por uma determinada força.

Quando aplicado como anel de vedação, o elastômero é confinado em um alojamento, e forçado a moldar-se e preencher as irregularidades da superfície das partes e qualquer folga existente, criando dessa maneira entre as partes a condição de "folga zero", promovendo o efetivo bloqueio do fluido. Dessa forma, quanto maior for a memória elástica do material, maior sua capacidade de vedação [8].

Outro fator determinante avaliado refere-se à instabilidade volumétrica do resíduo. Após as amostras serem submetidas aos ensaios de Imersão em água destilada $\left(168 \mathrm{~h} / 70^{\circ} \mathrm{C}\right)$ e óleo IRM $903\left(72 \mathrm{~h} / 70^{\circ} \mathrm{C}\right)$ não houve significativas alterações nos seus respectivos volumes. Dessa forma, constatou-se que não ocorreu o fenômeno de expansão característico do resíduo.

Isto ocorre pelo fato do processo de expansão ocorrer logo após a moagem, o que de fato torna o processo de micronização do resíduo uma alternativa pra se evitar o acúmulo deste nas siderúrgicas [4].

Portanto, procura-se com este projeto não somente difundir a utilização da escória de aciaria elétrica micronizada para outros setores industriais, mas enfatizar o seu processo de micronização, o qual pode transformar tal resíduo em um co-produto de alto valor comercial.

\section{REFERÊNCIAS}

1 PUGA, F.; MEIRELLES, B. Perspectivas de Investimentos na Indústria em 2010-2013. Banco Nacional de Desenvolvimento (BNDES). 2010 [acesso em 15 mai. 2015] Disponível em: http://www.bndes.gov.br/SiteBNDES/export/sites/default/bndes_pt/Galerias/Arquivos/co nhecimento/visao/Visao_79.pdf

2 CASELATO, L. Panorama de escória de aciaria no Brasil. Instituto Aço Brasil. 2010. [acesso em 15 mai. 2015]. Palestra apresentada no Seminário Internacional de Aplicação de Escória de Aciaria, Belo Horizonte, nov. 2010. Disponível em: http://www.feam.br/images/stories/arquivos/arquivossmrr/escoria/lucila_caselato.pdf CASELATO, L. Ações Institucionais da Siderurgia Brasileira para Disseminação do Uso das Escórias de Aciaria. 2004. [acesso em 10 mai. 2015]. Workshop: Gerenciamento de Resíduos Sólidos no Setor Minero-Metalúrgico, Rio de Janeiro, nov.2004. Disponível em: http://www.abmbrasil.com.br/cim/download/lucila_ibs.pps.

4 POLISSENI, A. Estudo da Viabilidade Técnica da Utilização de Esscória de Aciaria Elétrica Micronizada como Material Cimentício. 2005. 251 f. Tese (Doutorado em Engenharia Civil). Escola de Engenharia, Universidade Federal do Rio Grande do Sul. Porto Alegre, 2005.

5 ARAUJO, M. Ativação Química E Térmica De Escória De Aciaria Elétrica. 108 f. Programa De Pós-Graduação Em Engenharia Mecânica. Departamento De Pesquisa E Pós-Graduação, Universidade Tecnológica Federal Do Paraná. Curitiba. 2008. 
6 LIMA, L. A. Hormigones com escórias de horno eléctrico como áridos: propiedades, durabilidad y comportamiento ambiental. 1999. $265 \mathrm{f}$. Tesis(DoctoralenEnginyeria) Departament D'Enginyeria de laConstrucción, Escola Técnica Superior D'Enginyers de Camins, Canals i Ports, Universitat Politécnica de Catalunya, Barcelona.

7 ROCHA, E.; LOVISON, V.; PIEROZAN, N. Tecnologia De Transformação De Elastômeros. SENAI - FIERGS. 2 ${ }^{\mathrm{a} e d .}$. São Leopoldo -RS: 2007.

8 PARKER SEALS. Manual de O-ring. [acessado em 14 jun. 2015]. Catálogo 5700 BR. São Paulo, Mai 1997. Disponível em:

http://www.hipress.com.br/upload/catalogo/MANUALDEORING5700.pdf 